\title{
ONCOGRAM: study protocol for the evaluation of therapeutic response and survival of metastatic colorectal cancer patients treated according to the guidelines of a chemosensitivity assay, the Oncogramme ${ }^{\circledast}$
}

Muriel Mathonnet ${ }^{1,2^{*}}$ (D), Mathieu Vanderstraete ${ }^{3}$, Christophe Bounaix Morand du Puch ${ }^{3}$, Stéphanie Giraud ${ }^{3}$, Christophe Lautrette ${ }^{3}$, Mehdi Ouaissi ${ }^{4}$, Nicolas Tabchouri ${ }^{4}$, Abdelkader Taïbi ${ }^{1}$, Renaud Martin ${ }^{5}$, Isabelle Herafa ${ }^{6}$, Achille Tchalla ${ }^{7}$, Niki Christou ${ }^{1,2}$ and The ONCOGRAM trial investigators

\begin{abstract}
Background: Colorectal cancer is a major public concern, being the second deadliest cancer in the world. Whereas survival is high for localized forms, metastatic colorectal cancer has showed poor prognosis, with a 5-year survival barely surpassing $11 \%$. Conventional chemotherapies against this disease proved their efficiency and remain essential in first-line treatment. However, the large number of authorized protocols complexifies treatment decision. In common practice, such decision is made on an empirical basis, by assessing benefits and risks for the patient. In other words, there is currently no efficient means of predicting the efficacy of any chemotherapy protocol for metastatic colorectal cancer.

Methods/design: The use of a chemosensitivity assay, the Oncogramme ${ }^{\oplus}$, should help clinicians administer the best chemotherapy regimen to their patients. We hypothesize it would ultimately improve their survival. In this multicentred, prospective trial (ONCOGRAM), eligible patients with metastatic colorectal cancer are randomized to determine whether they will receive an Oncogramme ${ }^{\circledast}$. For clinicians whose patients benefited from the assay (arm A), results are used as a decision support tool. Patients not undergoing the Oncogramme ${ }^{\circledast}$ procedure are treated according to current practice, without the assistance of the assay (arm B). Primary outcome is 1-year progressionfree survival. Secondary outcomes include response rates, as well as 6-month and 1-year survival rates.
\end{abstract}

\footnotetext{
* Correspondence: muriel.mathonnet@unilim.fr

'Department of Digestive, General and Endocrinology Surgery, Dupuytren University Hospital, 2 Avenue Martin Luther King, Limoges, France

2EA3842 laboratory (CAPTuR: "Contrôle de l'Activation cellulaire, Progression Tumorale et Résistances thérapeutiques"), Limoges Medical School, 2 rue du docteur Marcland, Limoges, France

Full list of author information is available at the end of the article
}

(c) The Author(s). 2021 Open Access This article is licensed under a Creative Commons Attribution 4.0 International License, which permits use, sharing, adaptation, distribution and reproduction in any medium or format, as long as you give appropriate credit to the original author(s) and the source, provide a link to the Creative Commons licence, and indicate if changes were made. The images or other third party material in this article are included in the article's Creative Commons licence, unless indicated otherwise in a credit line to the material. If material is not included in the article's Creative Commons licence and your intended use is not permitted by statutory regulation or exceeds the permitted use, you will need to obtain permission directly from the copyright holder. To view a copy of this licence, visit http://creativecommons.org/licenses/by/4.0/ The Creative Commons Public Domain Dedication waiver (http://creativecommons.org/publicdomain/zero/1.0/) applies to the data made available in this article, unless otherwise stated in a credit line to the data. 


\begin{abstract}
Discussion: This study aims at investigating the clinical utility of the Oncogramme ${ }^{\circledR}$ as a decision support tool for the treatment of patients with metastatic colorectal cancer. If the Oncogramme ${ }^{\oplus}$ positively influenced patient overall survival and/or progression-free survival, it would be of great value for clinicians to implement this assay within the current landscape of personalized medicine tools, which include genomics and biomarker assays.
\end{abstract}

Trial registration: ClinicalTrials.gov identifier NCT03133273. Registered on April 28, 2017.

Keywords: Colorectal cancer, Oncogramme ${ }^{\oplus}$, ONCOGRAM, Metastatic, Functional assay, CSRA, Personalized medicine, Chemosensitivity

\section{Background}

Colorectal cancer (CRC) is a major public health concern, being the second leading cause of cancer-related mortality worldwide, with about 880,000 deaths each year [1]. CRC is tightly correlated to high human development index (HDI), with a higher incidence in Western Europe, North America, and Oceania. As a result, rises of both incidence and mortality were recently observed in countries considered as emerging such as China and Brazil [2]. Worldwide, however, a decreased overall mortality has been observed over the last three decades. This is mainly due to earlier and more effective detection methods, as well as better treatments [3]. This encouraging trend is obscured by the poor survival rate of patients with metastatic CRC (mCRC), which is around $11.4 \%$ [4]. Efforts are made to improve survival by developing more efficient treatments, but also personalized medicine tools to better evaluate patient tumour's phenotypic and genomic characteristics. For mCRC treatment, a wide panel of drug combinations are available. Selection of chemotherapy regimens relies on empirical decisions, balancing potential benefits and toxicity $[5,6]$. Current standards of care are combinations of 5-fluorouracile (5-FU) and folinic acid (FA, also known as leucovorin) with either oxaliplatin (FOLFOX), irinotecan (FOLFIRI), or both (FOLFIRINOX and FOLFOXIRI). These combinations may be supplemented with anti-VEGF (bevacizumab) or anti-EGFR (cetuximab or panitumumab) antibodies, depending on the tumour's $K R A S / N R A S / B R A F$ mutational status [7]. Relapsing, microsatellite instable (MSI) mCRC patients may also receive immune checkpoint inhibitors nivolumab or pembrolizumab $[8,9]$. When used as first-line treatment, doublet regimen FOLFIRI and FOLFOX show similar response rates and OS profiles, yet the latter's administration frequency is much higher and continuously increasing [10]. Also, in first-line setting, FOLFIRINOX performs better than other combinations [11]. However, it induces more severe side effects, which may lead to empirical dosing reduction or treatment discontinuation [12]; it is thus usually limited to more robust patients. In any case, there is currently no data available to indicate whether appropriately targeted untreated or relapsing patient subpopulations would benefit even more from either drug combination.

To assist clinicians in their decision-making process, chemosensitivity and chemoresistance assays (CSRA), as members of the larger family of functional assays, have been developed against a wide variety of cancers. They aim at predicting chemo-response based on ex vivo culture of a patient's own tumour sample. Numerous CSRA have been developed in the last three decades, reaching high technical and clinical accuracies [13]. Despite these encouraging results, CSRA are still considered as investigational, as underlined by the latest clinical practice guidelines published by the American Society of Clinical Oncology (ASCO) [14]. These recommendations result from insufficient clinical evidence. However, given the potential value of functional assays, the ASCO strongly encourages the implementation of randomized, controlled, prospective trials $[15,16]$.

The Oncogramme ${ }^{\circ}$, a CE-marked in vitro diagnostics medical device (IVD-MD) developed by the French company Oncomedics, is dedicated to cancer treatment decision support [17-19]. Briefly, it consists in the measurement of therapy-induced mortality on patient sample primary cultures using fluorescence microscopy. This test is fully standardized, allowing both reliability and a high success rate. When applied to $\mathrm{mCRC}$, the Oncogramme $^{\circ}$ directly evaluates drug combinations commonly used by oncologists, such as 5-FU, FOLFOX, FOLFIRI, or FOLFIRINOX. A pilot study performed on a cohort of patients with mCRC showed a sensitivity of $84.6 \%$ of the assay in predicting tumour response [20], which is sensibly higher to published literature on CRC chemosensitivity assays [21].

To our knowledge, most clinical studies involving functional assays are retrospective studies [13]. There is a pressing need for information about the utility of these assays in actively assisting clinicians in making a therapeutic decision [14]. The ONCOGRAM trial is a multicentric, randomized, two-arm, single-blind, prospective and interventional study that will give insights into the clinical value of the Oncogramme ${ }^{\circ}$, as well as into its potential as a trustable and reliable tool for treatment individualization by oncologists. 


\section{Methods/design \\ Objectives}

The primary outcome for this study is progression-free survival (PFS) 1 year following inclusion.

Secondary outcomes include the following:

- Response rate;

- 6-month and 1-year overall survival (OS);

- 6-month PFS;

- Incremental cost-effectiveness ratio (ICER): expressed in euros per year of life gained without occurrence of death or progression to 1 year of the adapted chemotherapeutic treatment according to the results of the Oncogramme ${ }^{\oplus}$ using the EQ5D-5 L scale;

- Incremental cost/utility ratio (ICUR): expressed in euros per quality-adjusted life year (QALY) gained at 1 year of the adapted chemotherapeutic treatment according to the results of the Oncogramme ${ }^{\bullet}$ using the EQ5D-5 L scale;

- Reasons for which clinicians did not follow results of the Oncogramme;

- Proportions of grade 3 to 5 adverse events (AE) according to the following classification: grade 1 , mild $\mathrm{AE}$; grade 2 , moderate $\mathrm{AE}$; grade 3 , severe $\mathrm{AE}$; grade 4, life-threatening or disabling $\mathrm{AE}$; grade 5 , death related to $\mathrm{AE}$.

The occurrence of an adverse event is reported immediately to the sponsor. Pregnancy is not an adverse event but is reported to the sponsor.

\section{Study population and design}

This is a randomized, two-arm, single-blind, prospective, interventional study, involving 13 French clinical centres with a competitive enrolment. Eligible patients must be at least 18 and have a pre-operatively or per-operatively diagnosed metastatic colon or rectal cancer. Staging must be confirmed histologically, and metastases must be measurable according to response evaluation criteria in solid tumours (RECIST 1.1) [22]. Patients must be able to be treated using a standard chemotherapy regimen, including 5-FU-based therapies FOLFOX, FOLFIRI and FOLFIRINOX (or FOLFOXIRI). Chemotherapies may be associated with targeted therapies such as antiangiogenic antibodies (bevacizumab), and anti-EGFR antibodies (panitumumab and cetuximab), suitable for patients with wild type BRAF/NRAS/KRAS tumours. Chemotherapy must have a curative or palliative aim.

Patients fulfilling any of the following criteria are excluded from the trial:

- Contraindication to paraclinical exploration;

- Contraindication to any chemotherapy treatment;
- Exclusive use of radiotherapy, targeted therapy or immunotherapy, or exclusive palliative support care;

- Women of childbearing age who do not use contraception; pregnant and breastfeeding women;

- Patients with a legal guardian; patients who are not capable of understanding the terms of the trial.

The study follows an intention-to-treat scheme: this means the clinical response of a patient will be analysed according to the group to which the patient was assigned through randomization, independently of the fact that the Oncogramme $^{\odot}$ chemosensitivity profile was actually utilized or not to treat this patient (Fig. 1). A slightly different scheme has been designed to allow suspected mCRC samples to be integrated into the study (Fig. 2).

Patients receive comprehensive information about the research prior to signing an informed consent form (ICF). They are subsequently randomized by the clinical centre where they receive treatment through a secured internet randomization platform. This platform is handled by the Limoges University Hospital biostatistics department (Centre d'Épidémiologie, de Biostatistique, et de Méthodologie de la Recherche, CEBIMER). The randomization software automatically determines the arm and provides clinical research associates and Oncomedics' personnel relevant information about each subject: patient's identification number, age and year of birth, sex, arm, name of clinician responsible for the randomization, clinical centre's name, date of ICF signature. Patient randomization is performed using the modules CSOnline and CSRandomization of the software Ennov Clinical v8.0.120 (Ennov, Floirac, France). Patients are allocated to each arm by the method of minimization, using age, gender and centre as stratification factors. All patient data obtained for or generated by the trial are recorded in case report forms, whose information is incorporated into a dedicated, secured database generated using Ennov Clinical and its CSDesigner module. A participant may withdraw or withdraw consent to participate in the research at any time. In this case, he/she will no longer be followed in the protocol but will continue to receive the best possible care.

Following randomization, follow-up visits occur on a regular basis: first before chemotherapy treatment, then after 3, 6, 9 and 12 months. EQ5D-5 L questionnaires are filled by patients after every post-chemotherapy visit (Table 1). Total study duration for every patient is 12 months.

If a patient withdraws their consent, all data will be removed from the database and will not be used for analysis. In case of study discontinuation, corresponding data might be kept if the patient authorizes it. In that context, primary and secondary outcomes will be evaluated at the date of discontinuation. 


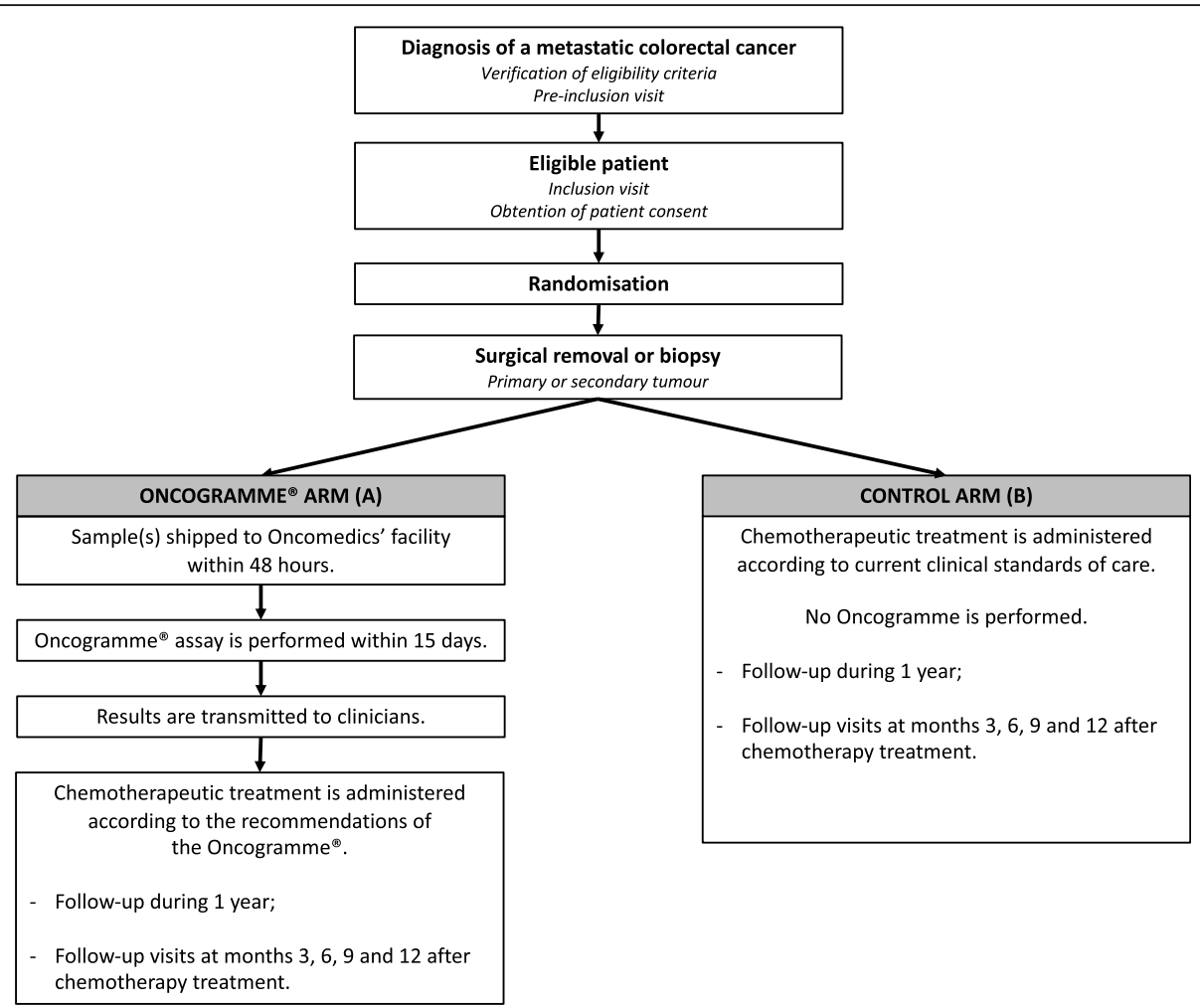

Fig. 1 ONCOGRAM diagram for confirmed mCRC samples. When $m C R C$ is already histologically diagnosed, inclusion and randomization occur before performing the Oncogramme ${ }^{\circledast}$. Oncomedics only receives samples and realizes the assays for patients already randomized in the Oncogramme ${ }^{\oplus}$ arm

The membership of the associated centres is maintained through monthly newsletters where the rate of inclusion is reported for each centre. A blog has been created. Individual webinars are held with all centres twice a year.

\section{Sample size calculation}

Based on a 1-year PFS of 15\% in the control arm, and $30 \%$ in the Oncogramme ${ }^{\circ}$-assisted arm, a log-rank test evaluated the total number of patients to include at 204 (with a significance level of 0.05 and a power of $80 \%$ ). Sample size ratio is 1:1, meaning that each arm should include 102 patients. Taking into consideration the eventuality of non-assessable patients, $20 \%$ has been added to the initial sample size, which eventually reached 256. Based on clinical data observed at Limoges hospital, it has been estimated that the study should include 5 patients per month, allowing to reach the target population of 256 patients in a 48 -month timeframe.

\section{Statistical analysis}

Intent-to-treat analyses will be performed by the CEBIMER with the use of SAS ${ }^{\circ} 9.3$ software. Results will be reported according to the CONSORT 2010 Statement [23]. 1-year PFS will be measured in each arm using the Kaplan-Meier method, with 95\% confidence intervals. Then, comparison between the two groups will be performed using a log-rank test. Starting point for PFS measurement is the randomization date. Ending points are $(i)$ event date for patients showing evidence of progression, (ii) date of last visit for lost to follow-up patients, and (iii) data cut-off date for living patients with no progression.

Secondary analyses will be performed as follows:

- Response rate: comparisons between response rates in control and Oncogramme arms will be performed using a $\mathrm{Chi}^{2}$ or a Fisher's exact test, depending on whether conditions of application of $\mathrm{Chi}^{2}$ are met;

- 6-month and 1-year OS: values will be estimated similarly as the primary outcome, using a Kaplan-Meier test with 95\% confidence intervals;

- Disease-free survival: Kaplan-Meier test with 95\% confidence intervals;

- Incremental cost-effectiveness ratio: ICER will be expressed as euros per QALY for patients who benefited from the Oncogramme; 


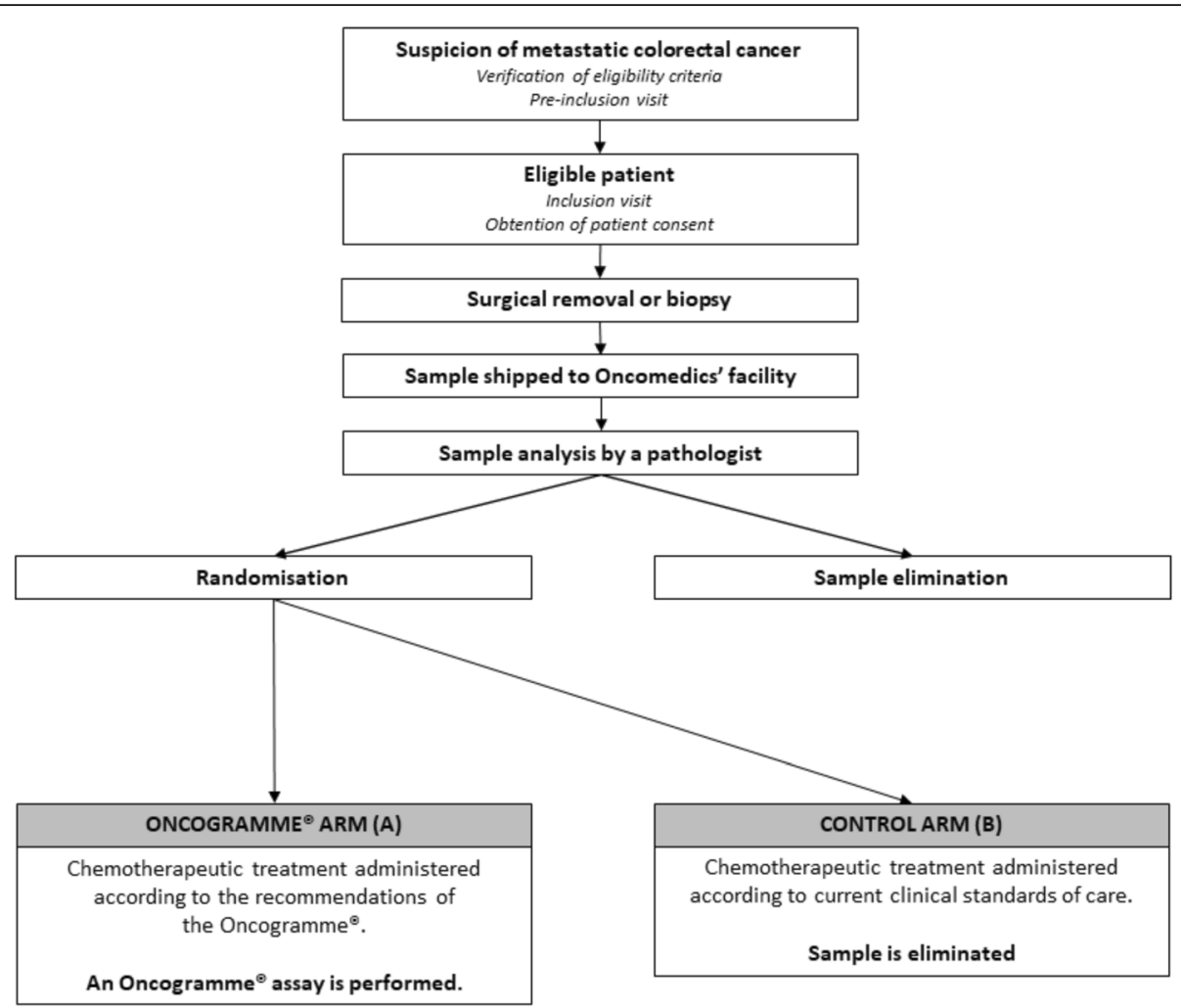

Fig. 2 ONCOGRAM diagram for suspected mCRC samples. Oncomedics receives and starts the Oncogramme ${ }^{\circledast}$ procedure on all samples not histologically qualified yet. Randomization occurs if the sample is confirmed as mCRC. Realization of the Oncogramme ${ }^{\oplus}$ is pursued only if the patient is randomized in the Oncogramme ${ }^{\oplus} \mathrm{arm}$. In all other cases, the sample is eliminated

- Comparison of EQ5D-5 L utility scores: comparison will be performed using a $t$ test or a non-parametric Mann-Whitney test, depending on whether conditions of application are met.
- Comparison of the proportions of grade 3 to 5 adverse events: $\mathrm{Chi}^{2}$ or a Fisher's exact test, depending on whether conditions of application of $\mathrm{Chi}^{2}$ are met.

Table 1 Overview of patient management steps during the whole course of the ONCOGRAM trial

\begin{tabular}{|c|c|c|c|c|c|}
\hline Patient management step & $\begin{array}{l}\text { Pre-inclusion } \\
\text { day - } 30 \text { to day - } \\
1\end{array}$ & $\begin{array}{l}\text { Inclusion } \\
\text { day } 0\end{array}$ & $\begin{array}{l}\text { Before first chemotherapy } \\
\text { treatment }\end{array}$ & $\begin{array}{l}\text { Follow-up } \\
\text { visits }\end{array}$ & $\begin{array}{l}\text { Final follow-up } \\
\text { visit } \\
\text { day } 0+12 \\
\text { months }\end{array}$ \\
\hline Information given to patient & $\checkmark$ & & & & \\
\hline Check eligibility criteria & $\checkmark$ & $\checkmark$ & & & \\
\hline Obtain patient's informed consent & & $\checkmark$ & & & \\
\hline Randomization & & $\checkmark$ & & & \\
\hline Clinical examination ${ }^{a}$ & & $\checkmark$ & & $\checkmark$ & $\checkmark$ \\
\hline Biological examination & $\sqrt{b}^{\mathrm{b}}$ & $\checkmark^{\mathrm{b}}$ & & $\sqrt{b}^{\mathrm{b}}$ & $\checkmark^{b}$ \\
\hline Paraclinical examination ${ }^{c}$ & & $\checkmark$ & & $\checkmark$ & $\checkmark$ \\
\hline EQ5D-5 L questionnaires & & $\checkmark^{d}$ & $\checkmark^{d}$ & $\checkmark^{d}$ & $\checkmark^{\mathrm{d}}$ \\
\hline $\begin{array}{l}\text { Search for adverse effects of } \\
\text { chemotherapies }\end{array}$ & & & & $\checkmark$ & $\checkmark$ \\
\hline
\end{tabular}

${ }^{a}$ Clinical examination: weight, height, cardiopulmonary checkup, comorbidities assessment, WHO performance status

${ }^{b}$ Albumin, protides, CEA, CA 19-9, complete blood count, liver function test (creatinine, AST, ALT, alkaline phosphatase, bilirubin, GGT): compulsory for inclusion and at months $1,3,6,9$ and 12. A urinary/blood pregnancy test is also performed for women of procreating age before inclusion

'Paraclinical examination includes if needed colonoscopy, MRI, PET scan, abdominal ultrasonography, thoraco-abdominopelvic CT

${ }^{d}$ EQ5D-5 $L$ questionnaires are filled by the patient before first chemotherapy, then at months 3, 6, 9 and 12 


\section{Procedure of the Oncogramme ${ }^{\oplus}$ Sample preparation and shipment}

Following exeresis, a fresh specimen containing tumour tissue is qualified by pathologists, then shipped to Oncomedics' laboratory according to UN3373 classification standards. The use of a dedicated transportation medium (OncoMiD-Via for colon, Oncomedics) allows preservation of sample quality and viability for further use. The ideal timeframe between patient surgery and sample processing should not exceed $48 \mathrm{~h}$ to ensure sample optimal quality. Only samples for patients assigned to arm A are sent to Oncomedics.

\section{Sample processing}

After decontamination, the tumour sample is dissociated using a proprietary method combining both mechanical and enzymatic steps $[17,19,20]$. Following dissociation, cell viability is measured by trypan blue exclusion assay (Merck). Then, the cell suspension is cultivated in a CRC-specific, defined (serum-free) medium (OncoMiD for colon, Oncomedics). Cells are incubated at $37^{\circ} \mathrm{C}$ under a $5 \% \mathrm{CO}_{2}$ atmosphere for 6-8 days, with medium renewal after 4 to 5 days. This step allows progressive elimination of non-tumoral cells to retrieve a majority of epithelial cells.

\section{Chemotherapy treatment}

Tumour cells are seeded in 8-well LabTek chamber slides (Thermo) at a concentration of $10^{5}$ cells per mL. For a given cell culture, five conditions are prepared in triplicate: untreated; 5-FU + FA; FOLFIRI (5-FU + AF + irinotecan); FOLFOX (5-FU +AF + oxaliplatin); FOLFIRINOX (5-FU + AF + irinotecan + oxaliplatin) (all chemotherapies provided by Merck). Critical chemotherapy concentrations were determined as previously described $[17,19,20]$. Cells are then incubated for $72 \mathrm{~h}$ at $37^{\circ} \mathrm{C}$ under a $5 \% \mathrm{CO}_{2}$ atmosphere before labelling.

\section{Labelling and mounting}

Following exposure to treatments, cell viability is assessed through a fluorescent triple labelling. Briefly, cells are incubated for $45 \mathrm{~min}$ in PBS containing $4 \mu \mathrm{M}$ acetomethoxy derivate of calcein and $0.1 \mu \mathrm{M}$ ethidium homodimer-1 (LIVE/DEAD ${ }^{\circ}$ viability/cytotoxicity kit, Life Technologies). Cells are then fixed at $22^{\circ} \mathrm{C}$ for 30 min using $4 \%$ formaldehyde in PBS (Merck). Subsequently, cell nuclei are stained with DAPI (Merck) at $22^{\circ} \mathrm{C}$ for $20 \mathrm{~min}$. Slides are dried before mounting with glycerol-gelatin mounting medium (Merck). Finally, slides are stored at $-20^{\circ} \mathrm{C}$ until readout.

\section{Readout and analysis}

Analysis is performed using a fluorescent upright microscope (Eclipse 80i, Nikon). For each well, several multi- channel fields are pictured over the whole surface using NIS-Elements BR 3.1 software (Nikon). Variable number of pictures are taken for each patient, to provide a sufficient number of cells and obtain statistically robust data. Cell mortality is then manually assessed based on fluorescence profiles. Sensitivity thresholds determined following a previous study (except for FOLFIRINOX) [20] are applied to cell death measurements to determine the sample's chemosensitivity to a particular drug combination. These thresholds correspond to cell mortality ratio values for which a tumour is considered as sensitive to a treatment : hence, if the ratio "cell mortality treatment $x /$ cell mortality untreated" is superior to "threshold treatment $x$, then the tumour is considered to be sensitive to the treatment. Otherwise, the tumour is considered to be non-sensitive.

\section{Use of the Oncogramme ${ }^{\circledR}$ results by clinicians}

Results of the Oncogramme are transmitted to clinicians in charge of the patient within 15 working days. This short time frame allows clinicians to use results of the Oncogramme ${ }^{\bullet}$ during multidisciplinary meetings determining the best treatment for each patient. It is worth noting that results of the Oncogramme ${ }^{\bullet}$, similar to other complementary diagnostics, represent a supplementary tool: the ultimate choice of a patient's treatment always proceeds from clinicians' decision. Noteworthy, clinicians must utilize the Oncogramme ${ }^{\circ}$ results only as an index of chemosensitivity. In this context, negative chemosensitivity results should not be interpreted as chemoresistance.

\section{Discussion}

Precision cancer medicine is a rapidly evolving concept that brings tools to help tailoring patient treatments. The implementation of such tests in common practice necessitates a clinical evidence-based framework to ensure their added value. Hence, as recommended by the ASCO [14], large randomized controlled clinical trials are needed to demonstrate the utility of companion diagnostics and functional assays such as CSRA. Available clinical evidence for functional assays is mostly retrospective and does not study the role of the assay in decision making. This clinical trial aims at bringing insights into the proactive role of such assays in facilitating clinicians' decisions. We hypothesize the use of the Oncogramme ${ }^{\circ}$ will improve the percentage of $\mathrm{mCRC}$ patients reaching 1 -year PFS from $15 \%$ to $30 \%$. We assume this would lead to a range of benefits for patients, including better quality of life, less adverse effects and, ultimately, OS improvement. Also, from a medicoeconomic standpoint, one can assume that choosing the right chemotherapy as soon as first-line regimens would 
diminish global costs of patients' care, notably by avoiding the administration of non-effective drugs.

Taken together, positive outcomes of the ONCOGRAM trial would strongly encourage the development of other Oncogramme ${ }^{\circ}$-based clinical studies on other malignant pathologies. Preclinical studies have already demonstrated the feasibility of the procedure with ovary and breast tumour samples [18, 19, 24].

\section{Trial status}

The current version of the protocol in use is $n^{\circ} 6.0$ (June 19, 2019). The first patient was enrolled on July 24, 2017. Recruitment is expected to end in July 2021. So far, 118 patients out of the 256 initially planned have been enrolled.

\section{Abbreviations}

CRC: Colorectal cancer; mCRC: Metastatic colorectal cancer;

CSRA: Chemosensitivity and resistance assay; PFS: Progression-free survival; OS: Overall survival; FA: Folinic acid; FOLFOX: FA + leucovorin + oxaliplatin; FOLFIRI: FA + leucovorin + irinotecan; FOLFIRINOX: FA + leucovorin + oxaliplatin + irinotecan; IVD-MD: In vitro diagnostics medical device; RECIST: Response evaluation criteria in solid tumours

\section{Acknowledgements}

The ONCOGRAM trial investigators:

CHU Limoges/CH Saint-Junien: B Marin, S Bouvier, S Durand-Fontanier, A Fabre, D Valleix, T Rivaille, F Fredon, S Derbal, P Carrier, R Daloko Lonfo, R Legros, S Lavau-Denes, V Lebrun-Ly, F Thuillier, P Engel, A Chaunavel, M Pradel; CHU Clermont-Ferrand: D Pezet (PI), A Dubois, C Pétorin, O Antomarchi, A Aboukassem, A Vimal-Baguet, B Gillet, B Mathieu, J Joubert-Zakeyh; Institut Bergonié (Bordeaux): S Evrard (PI), Y Becouarn, D Béchade, M Fonk, G DesoIneux, N Dauriat, M Agbo, M Louty; CHU Nîmes: F Borie (PI), S Lyubimova, V Phoutthasang, B Brunaud-Gagniard, Y Benadjaoud, N Rolland, L Letournoux, P Roger; CH Guéret: L Chen (PI), Z Amadou, C Christopoulous, G Nakahl, Y Souliman, MN Cirt, D Ducoux; Clinique des Cèdres (Brive-la-Gaillarde): PA Boisseau (PI), P Pardies, L Mesturoux; CH Brive-la-Gaillarde: L Vayre (PI), A Abdeh, F Teboul, R Landraud; CHU Tours: M Ouaissi (PI), E Salamé, N Tabchouri, T Lecomte, G Proutheau, S Guyetant; CHU Poitiers: D Tougeron (PI), A de Singly, A Ferru, R El Fadel, T Courvoisier, A Junca, E Frouin, L Rouleau, S Rafaert, A Rocher; CHU Amiens: J-M Regimbeau (PI), C Sabbagh, E Dumange, E Chive, D Lignier, N Siembida, B Chauffert, V Hautefeuille, D Chatelain; (CHU de La Martinique): E Rivkine

\section{Authors' contributions}

MM is the chief investigator. MM, CBMP, SG and CL conceived the study design and wrote the protocol proposal. MV and CBMP drafted the manuscript. All authors read and approved the final manuscript.

\section{Funding}

This clinical trial is supported by the French "Direction Générale de l'Offre de Soin" (DGOS) and the French "Institut National du Cancer" (INCa).

\section{Availability of data and materials}

The access to the protocol is possible with Clinical Trials (ClinicalTrials.gov). The participant-level dataset and statistical code will be accessible at the end of the inclusions.

\section{Declarations}

\section{Ethics approval and consent to participate}

The trial was approved by the "Comité de protection des personnes du SudOuest et Outre-Mer IV" (institutional review board) on July 3, 2017 (registration number: 2017-A00120-53). Written, informed consent to participate will be obtained from all participants.

Role of coordinating centre, endpoint adjudication committee, data management team: The coordinating centre is responsible for the logistical management of the orders and the follow-up of the use of the Oncogramme ${ }^{\circ}$, a CE-marked in vitro diagnostics medical device, developed by the French company Oncomedics, dedicated to cancer treatment decision support, the monitoring of the inclusions, and the communication with the associated centres. This trial does not require a steering committee because the number of stakeholders is limited. The Adjudication Committee is composed of 3 experts in the field of oncology and digestive surgery who did not participate in the study. The role of this committee is to determine whether or not the deaths of the included patients are attributable to the disease. The committee will make a blinded decision on the randomization arm at the end of the study.

A data monitoring committee has not been set up because this is an interventional research project with minor obligations and risks (category 2)

\section{Consent for publication}

The promoter of the study, i.e. the University Hospital of Limoges, has access to the source data and reports of all associated centres in order to guarantee the quality of the study results.

The database is created from the Ennov Clinical software. This database is hosted on a dedicated server at the Limoges University Hospital. The patient follow-up data-table of each centre can be made available to each investigator but cannot be used outside the framework of the trial.

\section{Competing interests}

$\mathrm{CL}$ and SG are cofounders of Oncomedics SAS and have equity positions in the company. MV and CMBP are employees of Oncomedics SAS. MM, NC, $\mathrm{MO}, \mathrm{NT}, \mathrm{AT}, \mathrm{RM}, \mathrm{IH}$ and AT as well as the ONCOGRAM trial investigators declare that they have no competing interests.

\section{Author details}

${ }^{1}$ Department of Digestive, General and Endocrinology Surgery, Dupuytren University Hospital, 2 Avenue Martin Luther King, Limoges, France. ${ }^{2}$ EA3842 laboratory (CAPTuR: "Contrôle de l'Activation cellulaire, Progression Tumorale et Résistances thérapeutiques"), Limoges Medical School, 2 rue du docteur Marcland, Limoges, France. ${ }^{3}$ Oncomedics SAS, 1 Avenue d'ESTER, Limoges, France. ${ }^{4}$ Department of Digestive, Oncological, Endocrine, Hepato-Biliary, Pancreatic and Liver Transplant Surgery, Trousseau University Hospital, Avenue de la République, Chambray-lès-Tours, France. ${ }^{5}$ Research and Innovation Bureau, Dupuytren University Hospital, 2 Avenue Martin Luther King, Limoges, France. ${ }^{6}$ Centre of Clinical Investigation 1435, Dupuytren University Hospital, 2 Avenue Martin Luther King, Limoges, France. ${ }^{7}$ Department of Clinical Geriatrics, Dupuytren University Hospital, Limoges, France.

Received: 10 December 2020 Accepted: 9 August 2021

Published online: 21 August 2021

References

1. Bray F, Ferlay J, Soerjomataram I, Siegel RL, Torre LA, Jemal A. Global cancer statistics 2018: GLOBOCAN estimates of incidence and mortality worldwide for 36 cancers in 185 countries. CA Cancer J Clin. 2018;68(6):394-424. https://doi.org/10.3322/caac.21492.

2. Arnold M, Sierra MS, Laversanne M, Soerjomataram I, Jemal A, Bray F. Global patterns and trends in colorectal cancer incidence and mortality. Gut. 2017: 66(4):683-91. https://doi.org/10.1136/gutjnl-2015-310912.

3. Marley AR, Nan H. Epidemiology of colorectal cancer. Int J Mol Epidemiol Genet. 2016:7(3):105-14

4. Brenner H, Kloor M, Pox CP. Colorectal cancer. Lancet. 2014;383(9927):1490502. https://doi.org/10.1016/S0140-6736(13)61649-9.

5. Lee JJ, Chu E. An update on treatment advances for the first-line therapy of metastatic colorectal cancer. Cancer J. 2007;13(5):276-81. https://doi.org/1 0.1097/PPO.0b013e3181570062.

6. Holch J, Stintzing S, Heinemann V. Treatment of metastatic colorectal cancer: Standard of care and future perspectives. Visc Med. 2016;32(3):17883. https://doi.org/10.1159/000446052.

7. Ikoma N, Raghav K, Chang G. An Update on Randomized Clinical Trials in Metastatic Colorectal Carcinoma. Surg Oncol Clin N Am. 2017;26(4):667-87. https://doi.org/10.1016/j.soc.2017.05.007.

8. Overman MJ, McDermott R, Leach JL, Lonardi S, Lenz HJ, Morse MA, et al. Nivolumab in patients with metastatic DNA mismatch repair-deficient or microsatellite instability-high colorectal cancer (CheckMate 142): an open- 
label, multicentre, phase 2 study. Lancet Oncol. 2017;18(9):1182-91. https:// doi.org/10.1016/S1470-2045(17)30422-9.

9. Marcus L, Lemery SJ, Keegan P, Pazdur R. FDA approval summary: Pembrolizumab for the treatment of microsatellite instability-high solid tumors. Clin Cancer Res. 2019;25(13):3753-8. https://doi.org/10.1158/10780432.CCR-18-4070.

10. Neugut Al, Lin A, Raab GT, Hillyer GC, Keller D, O'Neil DS, et al. FOLFOX and FOLFIRI Use in Stage IV Colon Cancer: Analysis of SEER-Medicare Data. Clin Colorectal Cancer. 2019;18(2):133-40. https://doi.org/10.1016/j.clcc.2019.01. 005.

11. Ychou M, Rivoire M, Thezenas S, Quenet F, Delpero JR, Rebischung C, et al, A randomized phase II trial of three intensified chemotherapy regimens in first-line treatment of colorectal cancer patients with initially unresectable or not optimally resectable liver metastases. the METHEP trial. Ann Surg Oncol. 2013. https://doi.org/10.1245/s10434-013-3217-x.

12. Deyme L, Barbolosi D, Gattacceca F. Population pharmacokinetics of FOLFIRINOX: a review of studies and parameters. Cancer Chemother Pharmacol. 2019;83(1):27-42. https://doi.org/10.1007/s00280-018-3722-5.

13. Blom K, Nygren P, Larsson R, Andersson CR. Predictive Value of Ex Vivo Chemosensitivity Assays for Individualized Cancer Chemotherapy: A MetaAnalysis. SLAS Technol. 2017;22(3):306-14. https://doi.org/10.1177/247263 0316686297.

14. Burstein HJ, Mangu PB, Somerfield MR, Schrag D, Samson D, Holt L, et al. American Society of Clinical Oncology clinical practice guideline update on the Use of chemotherapy sensitivity and resistance assays. J Clin Oncol. 2011:29(24):3328-30. https://doi.org/10.1200/JCO.2011.36.0354.

15. Hur H, Kim NK, Kim HG, Min BS, Lee KY, Shin SJ, et al. Adenosine triphosphate-based chemotherapy response assay-guided chemotherapy in unresectable colorectal liver metastasis. Br J Cancer. 2012;106(1):53-60. https://doi.org/10.1038/bjc.2011.469.

16. Cree IA, Kurbacher CM, Lamont A, Hindley AC, Love S, Cree IA, et al. A prospective randomized controlled trial of tumour chemosensitivity assay directed chemotherapy versus physician's choice in patients with recurrent platinum-resistant ovarian cancer. Anticancer Drugs. 2007;18(9):1093-101. https://doi.org/10.1097/CAD.0b013e3281de727e.

17. Loum E, Giraud S, Bessette B, Battu S, Mathonnet M, Lautrette C. Oncogramme, a new individualized tumor response testing method: Application to colon cancer. Cytotechnology. 2010;62(5):381-8. https://doi. org/10.1007/s10616-010-9298-5.

18. Giraud S, Loum E, Bessette B, Fermeaux V, Lautrette C. Oncogramme, a new promising method for individualized breast tumour response testing for cancer treatment. Anticancer Res. 2011;31(1):139-45.

19. Giraud S. Oncogramme, an Adapted Method for Individualized Tumour Response Testing of Ovary Cancer Treatments. J Cancer Res Ther Oncol. 2014. https://doi.org/10.17303/jcrto.2014.2.303.

20. Bounaix Morand du Puch C, Giraud S, Lautrette C, Nouaille M, Labrunie A, Luce $S$, et al. Chemotherapy outcome predictive effectiveness by the Oncogramme: Pilot trial on stage-IV colorectal cancer. J Transl Med. 2016. https://doi.org/10.1186/s12967-016-0765-4

21. Yoon YS, Kim JC. Recent applications of chemosensitivity tests for colorectal cancer treatment. World J Gastroenterol. 2014;20(44):16398-408. https://doi. org/10.3748/wjg.v20.i44.16398.

22. Eisenhauer EA, Therasse P, Bogaerts J, Schwartz LH, Sargent D, Ford R, et al. New response evaluation criteria in solid tumours: Revised RECIST guideline (version 1.1). Eur J Cancer. 2009. https://doi.org/10.1016/j.ejca.2008.10.026.

23. Schulz KF, Altman DG, Moher D. CONSORT 2010 statement: Updated guidelines for reporting parallel group randomized trials. BMJ. 2010; 340(mar23 1):c332. https://doi.org/10.1136/bmj.c332.

24. Giraud S, Bounaix Morand du Puch C, Fermeaux V, Guillaudeau A, Lautrette C. Oncogramme responses of breast tumour cells treated with herceptin correlate with HER2/C-ERB B2 pathological status. Anticancer Res. 2012;32: $1323-5$.

\section{Publisher's Note}

Springer Nature remains neutral with regard to jurisdictional claims in published maps and institutional affiliations.

\section{Ready to submit your research? Choose BMC and benefit from}

- fast, convenient online submission

- thorough peer review by experienced researchers in your field

- rapid publication on acceptance

- support for research data, including large and complex data types

- gold Open Access which fosters wider collaboration and increased citations

- maximum visibility for your research: over $100 \mathrm{M}$ website views per year

At BMC, research is always in progress.

Learn more biomedcentral.com/submissions 